\title{
CURARE AND CURARE-LIKE PRODUCTS IN CATARACT SURGERY*
}

\author{
BY \\ L. P. AGARWAL \\ Department of Ophthalmology, Medical College, Agra, India
}

AfTER the presentation of the previous report (Agarwal and Mathur, 1952) on the use of d-tubocurarine chloride in muscular relaxation during cataract operations, it was decided to assess the relative merits and demerits of curare and curare-like products. A further 75 cases were studied, and both local and general effects were noted with the following products, each in 25 cases:

(1) d-Tubocurarine chloride.

(2) Dimethyl tubocurarine iodide.

(3) Gallamine triethiodide.

The doses were calculated on the following basis :

(1) $1 \mathrm{mg}$. d-tubocurarine chloride -7 units.

(2) $1 \mathrm{mg}$. dimethyl tubocurarine iodide -21 units.

(3) $16 \mathrm{mg}$. gallamine triethiodide -21 units.

The curare and curare-like products were assayed by the "head-drop cross-over test " in rabbits.

\section{PhaRmaCology}

Bernard (1865) reported that curare causes paralysis by its action on the myoneural junction of striated muscles by nullifying the action of acetyl choline on individual muscle fibres. It has no action on sensory nerves nor on the central nervous system. In low doses the general muscle tone is quietened, a mild paresis follows, and finally complete paralysis occurs, indicating that the interference at the nerve ending is purely quantitative. The curare has its full manifest effect in about 5 minutes and the effect lasts for about 30 minutes. It acts by intravenous administration. d-Tubocurarine chloride in larger doses affects the muscles supplied by the autonomic nervous system by the same mechanism as that by which it affects the striated muscles. Gallamine triethiodide, even in large doses, has little action on the autonomic nervous system and does not give rise to histaminoid reactions. Depierre (1947) and Hingson and others (1949) feel that dimethyl tubocurarine iodide causes no respiratory embarrassment even in large doses.

The action of all these compounds is completely reversed by anticholineesterase agents.

* Received for publication April 9, 1953. 


\section{Clinical Investigations}

The indications and contraindications of these drugs have already been listed in a previous report (Agarwal and Mathur, 1952).

Material. -75 cases of cataract were given one of these drugs and the effects were noted. No selection of cases was done except in patients in whom curare products were contraindicated.

Method.-Routine preparation was carried out. Luminal was used as a premedicant (1 gr. at bed time the night before and $1 \mathrm{gr}$. an hour before the operation). Atropine $1100 \mathrm{gr}$. was given 30 minutes before operation. Topical anaesthesia was given by 2 per cent. anethaine four times every 5 minutes. Curare was then administered by the intravenous route into a vein in the cubital fossa. Oxygen. adrenaline, eserine, prostigmine, laryngoscope, and intratracheal intubation requirements were kept ready for emergencies.

Dose. -20 units curare or its equivalent were given in one minute, then 10 units every half minute until paresis began to appear; the administration was continued till the desired effect was obtained (Table I).

TABLE I. DOSAGE

\begin{tabular}{|c|c|c|c|c|c|c|c|}
\hline \multirow{2}{*}{ Drug Employed } & \multicolumn{3}{|c|}{ Dose for Ptosis } & \multicolumn{3}{|c|}{ Total Dose } & \multirow{2}{*}{$\begin{array}{l}\text { No. of } \\
\text { cases } \\
\text { tried }\end{array}$} \\
\hline & Min. & Max. & Average & Min. & Max. & Average & \\
\hline $\begin{array}{ll}\text { d-Tubocurarine chloride } & \ldots \\
\text { Gallamine triethiodide } & \ldots \\
\text { Dimethyl tubocurarine iodide... }\end{array}$ & $\begin{array}{l}20 \\
20 \\
12\end{array}$ & $\begin{array}{l}50 \\
37 \\
32\end{array}$ & $\begin{array}{l}32 \\
26 \\
22\end{array}$ & $\begin{array}{l}35 \\
26 \\
20\end{array}$ & $\begin{array}{l}70 \\
47 \\
42\end{array}$ & $\begin{array}{l}50 \\
39 \\
33\end{array}$ & $\begin{array}{l}25 \\
25 \\
25\end{array}$ \\
\hline
\end{tabular}

\section{Observations (Tables II and III)}

(i) Blood pressure, depth and rate of respiration, pulse rate, and pupillary reactions.

(ii) Tension, blinking reflex, ptosis, and ocular motility.

(iii) General muscular tone and relaxation.

(iv) Time after which maximum effects were obtained and for which effects lasted.

TABLE II. TIME OBSERVATIONS

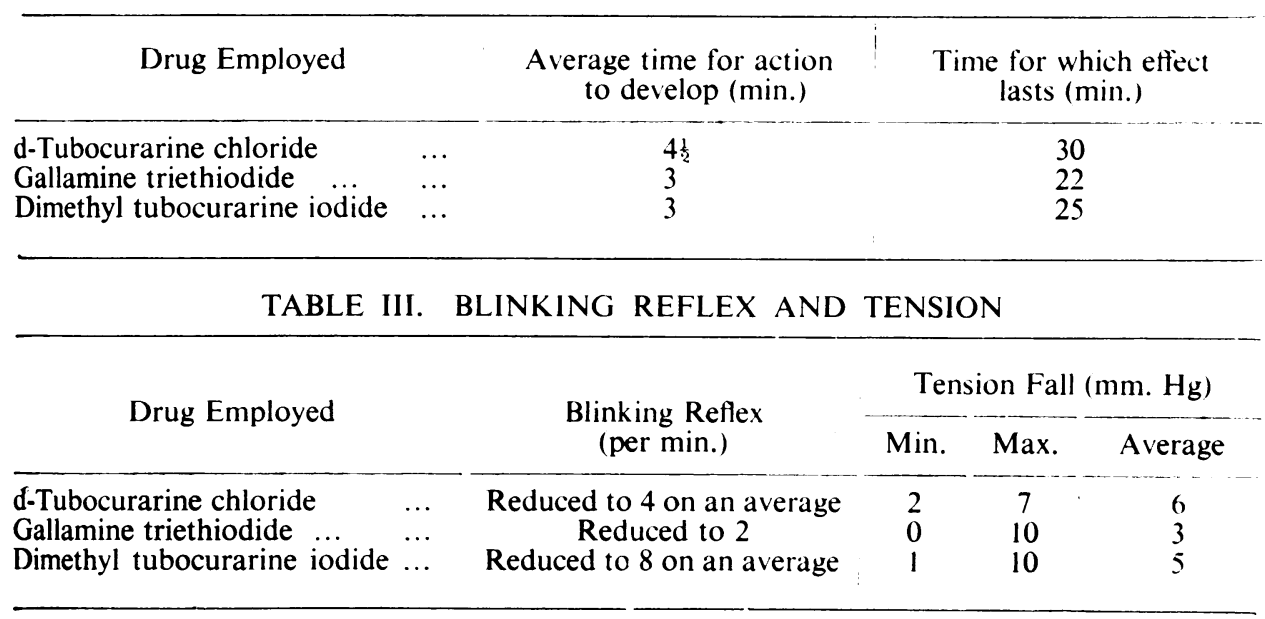


The total dose did not show any relationship to weight, age, or sex of patient; this is in agreement with Drucker and others (1951) and Agarwal and Mathur (1952) and contrary to Roche (1950) who advocated $\frac{1}{2}$ unit per lb. bodyweight.

Other Effects.-These patients showed no ocular prominence nor any evidence of sympathetic paralysis. There was no change in the pupillary size. The ocular motility was reduced to command movements. The findings were constant for all the three drugs, in agreement with Drucker and others (1951) and Agarwal and Mathur (1952).

General Effects.-With all these drugs the patients did not exhibit any change in cerebral state of consciousness. There was no cerebral depression. With d-tubocurarine chloride a few cases showed increased respiration, though in most of them the rate was unchanged. The depth of respiration showed no significant change. Similar findings were obtained by dimethyl tubocurarine iodide. The respiration with this drug was more regular and easy as compared with d-tubocurarine chloride. With gallamine triethiodide in many cases there was an increase in the respiratory rate and the depth of respiration showed a decrease, indicating that there was a lessening of the vital capacity. With d-tubocurarine chloride and dimethyl tubocurarine iodide the changes in pulse and in blood pressure were insignificant, whereas with gallamine triethiodide there was an increase both in systolic and diastolic blood pressure as well as in pulse rate, indicating that there was some effect on the autonomic nervous system in the form of sympathetic stimulation. The general muscular relaxation was most pronounced by dimethyl tubocurarine iodide and least by gallamine triethiodide.

\section{Discussion}

Curare and curare-like products act by relaxation of skeletal muscles and have no anaesthetic properties. These drugs are best used by intravenous injection. Their topical or local use is not recommended. In the dosage as ordinarily used in ophthalmic surgery they have no autonomic action, with the exception of gallamine triethiodide. The action of gallamine triethiodide on the autonomic nervous system is within safe limits, but the drug requires to be used with greater caution. From this point of view, dimethyl tubocurarine iodide appears to be safest.

The dosage employed varies from 20 to 70 units. On an average smaller doses of dimethyl tubocurarine iodide are required. There is a small fall in intra-ocular pressure with all three drugs in cataract cases.

Kirby (1950), Roche (1950), Clark (1949), Cordes and Mullen (1951), and Agarwal and Mathur (1952) have advocated their cautious use in cataract surgery.

\section{SUMMARY}

(1) The technique of administration is described.

(2) The action of three drugs is compared (d-tubocurarine chloride, gallamine triethiodide, and dimethyl tubocurarine iodide). 
(3) The muscular relaxation, allaying of apprehension, and limitation of $\frac{O}{0}$ ocular movements caused by the curare-like drugs enable them to be used with safety in cataract extraction without vitreous prolapse.

(4) Dimethyl tubocurarine iodide is the safest of the three.

(5) The use of curare as an adjuvant in cataract surgery is confirmed.

We are grateful to Abbotts Laboratories, Chicago, U.S.A., and Burroughs, Wellcome, $\frac{C}{0}$ England, for the supply of d-tubocurarine chloride, to the Eli Lilly Co.., Indiana, U.S.A., for $\overline{\bar{c}}$ the supply of dimethyl tubocurarine iodide, and to May and Baker, England, for the gallamine triethiodide.

\section{REFERENCES}

Agarwal, L. P., and Mathur, S. P. (1952). British Journal of Ophthalmology, 36, 603.

Bernard, C. (1865). Bull. gén. Thér., Paris, 69, 23.

Clark, W. B. (1949). Watson Gailey Eye Foundation Quarterly, 1, 34.

Cordes, F. C., and Mullen, R. S. (1951). Amer. J. Ophthal., 34, 557.

Depierre, F. (1947). C.R. Acad. Sci., 225, 956.

Drucker, A. P., Sadove, M. S., and Unna, K. R. (1951). Amer. J. Ophthal., 34, 543.

Hingson, R. A., Stoelting, V. K., Graf, J. P., and Vieira, Z. (1949). Curr. Res. Anesth., 忍 $28,130$.

KirBy, D. B. (1950). Arch. Ophthal., Chicago, 43, 678.

Roche, J. R. (1950). Amer. J. Ophthal., 33, 91. 